\title{
Child-Pugh A-B7 Cirrhosis
}

National Cancer Institute

\section{Source}

National Cancer Institute. Child-Pugh A-B7 Cirrhosis. NCI Thesaurus. Code C148151.

An indication that Child-Pugh scores ranging from A (scores 5 or 6 ) to B7 (score 7) for liver cirrhosis will be considered for trial inclusion. 